\title{
Amplification of the Insulin-Like Growth Factor 1 Receptor Gene Is a Rare Event in Adrenocortical Adenocarcinomas: Searching for Potential Mechanisms of Overexpression
}

\author{
Tamaya Castro Ribeiro, ${ }^{1}$ Alexander Augusto Jorge,, ${ }^{1,2}$ Madson Q. Almeida, ${ }^{3}$ \\ Beatriz Marinho de Paula Mariani, ${ }^{1}$ Mirian Yumi Nishi, ${ }^{1}$ Berenice Bilharinho Mendonca, ${ }^{1}$ \\ Maria Candida Barisson Villares Fragoso, ${ }^{3}$ and Ana Claudia Latronico ${ }^{1}$ \\ ${ }^{1}$ Unidade de Endocrinologia do Desenvolvimento, Laboratório de Hormônios e Genética Molecular LIM42, Brazil \\ ${ }^{2}$ Unidade de Endocrinologia Genética/LIM25, Brazil \\ ${ }^{3}$ Unidade de Suprarrenal, Disciplina de Endocrinologia e Metabologia, Hospital das Clínicas da Faculdade de Medicina da \\ Universidade de São Paulo, São Paulo, Brazil \\ Correspondence should be addressed to Ana Claudia Latronico; anacl@usp.br
}

Received 27 March 2014; Accepted 16 June 2014; Published 10 July 2014

Academic Editor: Maricilda Palandi de Mello

Copyright (C) 2014 Tamaya Castro Ribeiro et al. This is an open access article distributed under the Creative Commons Attribution License, which permits unrestricted use, distribution, and reproduction in any medium, provided the original work is properly cited.

\begin{abstract}
Context. IGF1R overexpression appears to be a prognostic biomarker of metastatic pediatric adrenocortical tumors. However, the molecular mechanisms that are implicated in its upregulation remain unknown. Aim. To investigate the potential mechanisms involved in IGF1R overexpression. Patients and Methods. We studied 64 adrenocortical tumors. IGF1R copy number variation was determined in all patients using MLPA and confirmed using real time PCR. In a subgroup of 32 patients, automatic sequencing was used to identify IGF1R allelic variants and the expression of microRNAs involved in IGF1R regulation by real time PCR. Results. IGF1R amplification was detected in an adrenocortical carcinoma that was diagnosed in a 46-year-old woman with Cushing's syndrome and virilization. IGF1R overexpression was demonstrated in this case. In addition, gene amplification of other loci was identified in this adrenocortical malignant tumor, but no IGF1R copy number variation was evidenced in the remaining cases. Automatic sequencing revealed three known polymorphisms but they did not correlate with its expression. Expression of miR100, miR-145, miR-375, and miR-126 did not correlate with IGF1R expression. Conclusion. We demonstrated amplification and overexpression of IGF1R gene in only one adrenocortical carcinoma, suggesting that these combined events are uncommon. In addition, IGF1R polymorphisms and abnormal microRNA expression did not correlate with IGF1R upregulation in adrenocortical tumors.
\end{abstract}

\section{Introduction}

Adrenocortical tumors are rare endocrine malignancies [1]. However, the incidence of these tumors is remarkably high in Southern Brazil, where it is estimated to be $10-15$ times greater than the worldwide incidence $[2,3]$. These tumors can occur in all age groups and have been characterized as having a bimodal age distribution, with the first peak occurring before 5 years of age and the second between the fourth and fifth decades [3].

The insulin-like growth factor (IGF) signaling system plays an important role in the growth and development of many tissues, including the adrenal gland [4]. Insulin-like growth factors are mitogens that regulate cell proliferation, differentiation, and apoptosis by interacting with the IGF1 receptor (IGF1R) [5]. This system has also been implicated in various pathophysiological conditions and is thought to play a particular role in tumorigenesis [6]. The IGF1R pathway is important in promoting oncogenic transformation, growth, and survival of cancer cells [7], and IGFIR overexpression has been demonstrated in many cancers $[8,9]$.

We previously demonstrated IGFIR overexpression in $65 \%$ of children and $13 \%$ of adults with adrenocortical tumors 
TABLE 1: Clinical characteristics of 64 patients with adrenocortical tumors.

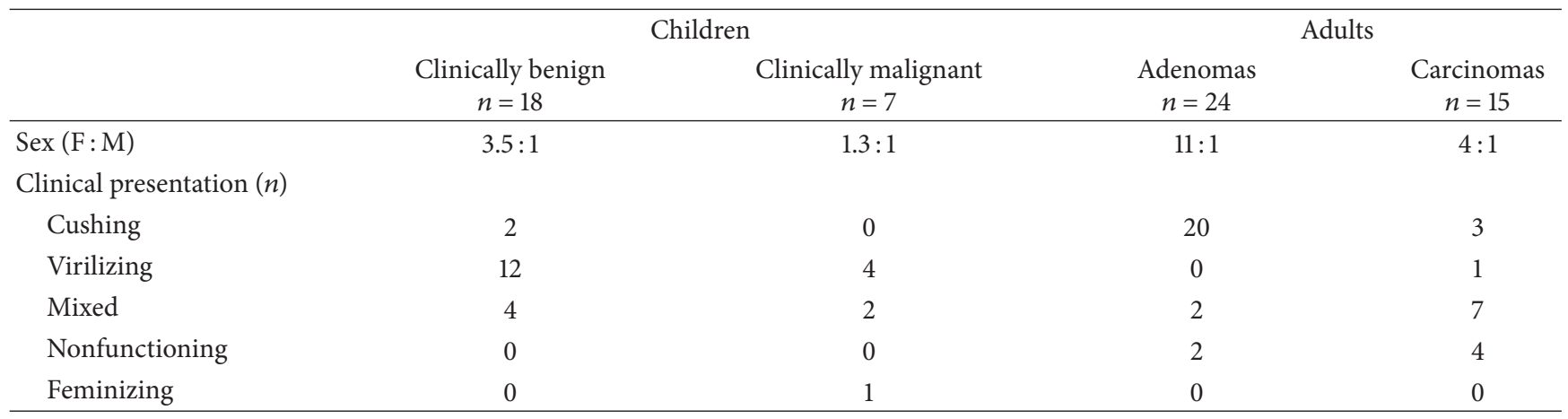

F: female; M: male.

[10]. Interestingly, this IGF1R upregulation was a predictor of metastases in children with adrenocortical tumors. Additionally, a selective IGF1R kinase inhibitor exhibited antitumor effects in adult and pediatric adrenocortical tumor cell lines, suggesting that IGF1R inhibitors represent a promising therapy for human adrenocortical carcinoma [10]. The IGF1R upregulation was confirmed in another cohort of pediatric patients [11]. The molecular mechanisms that lead to increased IGF1R expression in these tumors remain unexplained. In this study, we investigated whether IGF1R gene amplification and allelic variations could be implicated in $I G F 1 R$ upregulation. In addition, the expression of four distinct microRNAs (miRNA) that were involved in IGF1R regulation was evaluated.

\section{Patients}

The study included 64 Brazilian patients with sporadic adrenocortical tumors (Table 1). Written informed consent, as approved by the Ethics Committee of the Hospital of Clinics from the University of São Paulo, São Paulo, SP, Brazil, was obtained from all participants in this study. The consent was acquired directly from the subject if he/she was an adult or from the parent/guardian otherwise. Samples of sporadic adrenocortical tumors were obtained from 25 children and adolescents (18 girls and 7 boys; 1 to 18 years of age) and 39 adult patients (34 women and 5 men; 19 to 73 years of age). The diagnosis of malignancy in the pediatric group was established in 8 of the 25 adrenocortical tumors by advanced tumor stage (III or IV) and/or poor clinical outcome. Adult adrenocortical tumors were classified according to the Weiss criteria and included 23 adrenocortical adenomas (Weiss score $<3$ ) and 16 carcinomas (Weiss score $\geq 3)$. IGF1R expression was previously studied in 45 patients ( 24 children/adolescents and 21 adults) using real time PCR [10], and the overexpression of this receptor was observed in 17 children and 5 adults [10]. In 32 out of these 45 patients automatic sequencing was used to identify IGF1R allelic variants and the expression of microRNAs involved in IGF1R regulation was determined by real time PCR. Eight normal adrenal gland cortices, which were obtained from children and adults (range of age: 1 to 72 years) during renal surgery or autopsies, were used as controls. The fragments of adrenal cortices were properly selected by an experienced pathologist.

\section{Molecular Analysis}

3.1. DNA Extraction. Genomic DNA was extracted from frozen tumor samples using a Wizard Genomic DNA Purification Kit (Promega, WI, USA) and was stored at $-35^{\circ} \mathrm{C}$. The concentration and purity of the genomic DNA were measured, using spectrophotometer at an absorbance of 260 and $280 \mathrm{~nm}$.

3.2. Multiplex Ligation-Dependent Probe Amplification (MLPA). The IGF1R copy number of the adrenocortical tumors samples was measured using the SALSA MLPA kit P217 IGF1R (MRC-Holland, Amsterdam, Netherlands). This molecular assay was designed to detect deletions/duplications of one or more exons of the IGF1R (chromosome 15q26) and IGFBP3 (chromosome 7p13) genes. The P217 IGF1R probe mix contained 22 specific probes for IGF1R, 5 probes for IGFBP3, and 9 control probes. The FGFR4 and NSD1 genes analysis was performed using the SALSA MLPA kit P026-C1 Sotos (MRC-Holland, Amsterdam, The Netherlands), which contains two probes for FGFR4 gene and 24 probes for NSD1 gene (5q35.1). MLPA was performed with a total of $200 \mathrm{ng}$ of genomic DNA for each sample, as previously described [12]. The PCR products were submitted to capillary electrophoresison an ABI Prism 310 Genetic Analyzer (PE Applied Biosystems, The Perkin-Elmer Corporation, CA, USA), and the MLPA results were analyzed using the Genescan 3.7 software and further evaluated using the Excel spreadsheet software (Microsoft Corporation, Redmond, WA, USA). The tumor sample normalized peak height was then divided by the average normalized peak height of normal adrenals. Dosage quotient areas outside the range of 0.70-1.3 were considered abnormal. In addition, visual comparison of peak profiles was performed, three control samples were included in each MLPA experiment, and all results were confirmed by two independent tests.

3.3. SYBR Green Real Time PCR. SYBR Green real time PCR for the IGF1R gene (GenBank accession number 
NC_000015.9 for genomic and NM_000875.3 for mRNA sequences) was used to confirm the MLPA results for all of the adrenocortical tumors that were studied. The candidate gene copy number was measured using an ABI Prism 7000 instrument (Applied Biosystems, Forster City, CA, EUA). The Niemann-Pick disease type $\mathrm{Cl}$ gene (NPC1) (GenBank accession number NC_000018.9 for genomic and NM_000271.4 for mRNA sequences) was used as a house-keeping gene, and specific forward and reverse primers for IGF1R were used. The PCR was performed in $25 \mu \mathrm{L}$ containing $2.5 \mu \mathrm{L}$ of DNA (50 ng), 10 pmol of each primer, and the power SYBR Green PCR master mix (Applied Biosystems, Forster, CA). The thermal cycling conditions consisted of denaturation for $10 \mathrm{~min}$ at $95^{\circ} \mathrm{C}$, followed by 40 cycles of denaturation for $15 \mathrm{sec}$ at $95^{\circ} \mathrm{C}$ and annealing/extension for $1 \mathrm{~min}$ at $60^{\circ} \mathrm{C}$. A cycle threshold (CT) value in the linear range of amplification was selected for each sample in triplicate and normalized to NPC1. The IGF1R dosage was determined using the $2^{-\Delta \Delta C T}$ method [13]. The normalized value $(\Delta \mathrm{CT})$ for each tumor sample was then compared with the mean $\Delta \mathrm{CT}$ of five normal adrenals to generate a fold change ratio (normal $=1$ ) that was multiplied by 2 to obtain the copy number (normal $=2$ ).

3.4. IGF1R Sequence Analysis. IGF1R sequence analysis was performed in 32 (19 children-adolescents and 13 adults; 19 adenomas and 13 carcinomas) of 64 patients with adrenocortical tumors. Among these patients, 18 (52.6\%) exhibited $I G F 1 R$ overexpression. The entire coding region and exonintron boundaries of IGF1R were amplified from genomic DNA using PCR. The oligonucleotide sequences and PCR conditions are available upon request. The PCR products were pretreated with a combination of shrimp alkaline phosphatase and exonuclease I (United States Biochemical Corp., Cleveland, $\mathrm{OH}$ ) and directly sequenced using the BigDye TM terminator cycle sequencing ready reaction kit (PE Applied Biosystems, Foster City, CA) in an ABI Prism 310 automatic sequencer.

3.5. Expression of MicroRNAs. Some microRNAs can regulate IGF-1R expression. Four microRNAs that were related to IGF1R regulation were selected: miR-100, miR-145, miR375, and miR-126 [11, 14-16]. MicroRNA analysis was performed in 32 samples of adrenocortical tumors and in the same tumors that were submitted to automatic sequencing. To measure microRNA expression, RNA was extracted and quantitative real time PCR was performed. Singlestranded cDNA was synthesized from $1 \mathrm{mg}$ of total RNA using Megaplex RT Primers, Human Pool A v2.1 (PN 4399966, Applied Biosystems), and the TaqMan MicroRNA Reverse Transcription Kit (PN 4366596, Applied Biosystems). Twenty-five nanograms of cDNA was used as a template in a $20-\mu \mathrm{L}$ PCR reaction, and the PCR products were amplified using specific primers (TaqMan MicroRNA Assays: hsa-mir100-ID: 002142, hsa-mir 145-ID: 002278, has-mir375ID: 000564, has-mir126-ID: 002228, Applied Biosystems) and the Taqman Universal Master Mix II, with no UNG (PN 4440040, Applied Biosystems). The PCR products were detected using the ABI Prism 7000 Sequence Detection
System (Applied Biosystems). RNU 44 (ID: 001094, Applied Biosystems) and RNU 48 (ID: 001006, Applied Biosystems) were used as house-keeping genes. The relative expression levels were analyzed using the $2^{-\Delta \Delta \mathrm{CT}}$ method. A commercial pool of normal human adrenals RNA was used as a reference sample (Clontech, Palo Alto, CA).

3.6. P53 Analysis. Genomic DNA was extracted from frozen tumor specimens using a QIAmp DNA mini Kit (QIAGEN, Hilden, Germany). The entire exon 10 was amplified by PCR using the following intronic primers: $5^{\prime}$ GCTGTATAGGTACTTGAAGTGCAG- ${ }^{\prime}$ and $5^{\prime}$-GATGAGAATGGAATCCTATG-3' . The amplification protocol consisted of denaturing at $94^{\circ} \mathrm{C}$ for $5 \mathrm{~min}$, followed by 35 cycles consisting of annealing at $50^{\circ} \mathrm{C}$ for $30 \mathrm{sec}$, primer extension at $72^{\circ} \mathrm{C}$ for $30 \mathrm{sec}$, and denaturing at $94^{\circ} \mathrm{C}$ for $30 \mathrm{sec}$. All amplified fragments were examined on $1 \%$ agarose gel electrophoresis. The PCR products were pretreated with an enzymatic combination of exonuclease I and shrimp alkaline phosphatase (United Stated Biochemical Corp., Cleveland, $\mathrm{OH}$ ) and directly sequenced using the BigDye terminator cycle sequencing ready reaction kit (PE Applied Biosystems, Foster City, CA) in an ABI PRISM 310 automatic sequencer (Perkin-Elmer Corp.).

\section{Results}

4.1. IGF1R Copy Number. IGF1R amplification was detected using MLPA and confirmed using real time PCR in an adrenocortical carcinoma that was diagnosed in a 46-yearold female patient with Cushing's syndrome associated with clinical virilization (Figure 1). The tumor's size was $10 \times$ $8 \times 6 \mathrm{~cm}$, and it was classified as ENSAT stage III and presented a Weiss score of 7 upon histopathological analysis. IGF1R mRNA levels were 5 times higher in this tumor than in the normal total adrenal gland pool. Additionally, the amplification of the IGFBP3, FGFR4 (data not shown), and NSD1 (data not shown) genes was also detected in this carcinoma, but IGF1R amplification was not demonstrated in the remaining cases with adrenocortical tumors.

4.2. IGF1R Sequence Analysis. Three distinct previously described exomic polymorphisms were detected in IGF1R: exon 11 rs_3743262 (10.5\%, genotype frequency), exon 16 rs_2229765 (65.8\%, genotype frequency), and exon 21 rs_17847203 (7.9\%, genotype frequency). No correlation between the IGF1R variants and their expression was demonstrated in the adrenocortical tumors. In addition, another 6 previously known polymorphisms were identified in the intronic regions (rs_7174918, rs_2272037, rs_951715, rs_1464430, rs_4486868, and rs_2593053).

4.3. MicroRNA Expression. Real time PCR analysis revealed that miR-100 (median 0.3 (from 0.07 to 1.97)) and 375 (median 0.05 (from 0.01 to 0.27 )) were downregulated in adrenocortical tumors. This reduction was observed in benign and malignant tumors and was not associated with increased expression of IGF1R. miR-145 (median 2.2 (from 


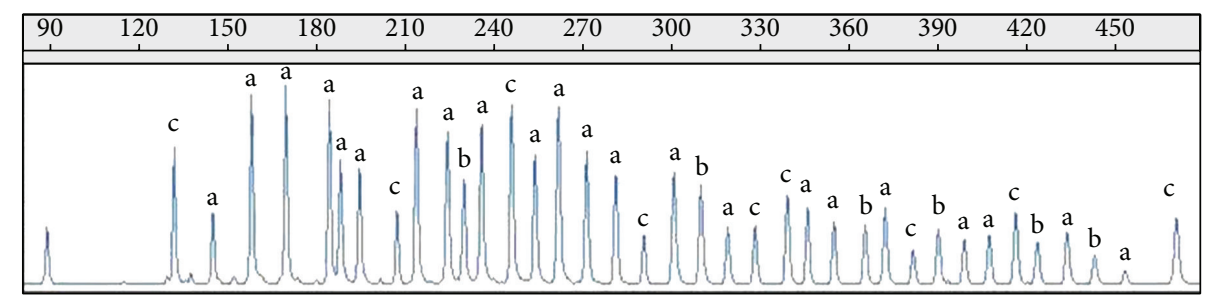

(IA)

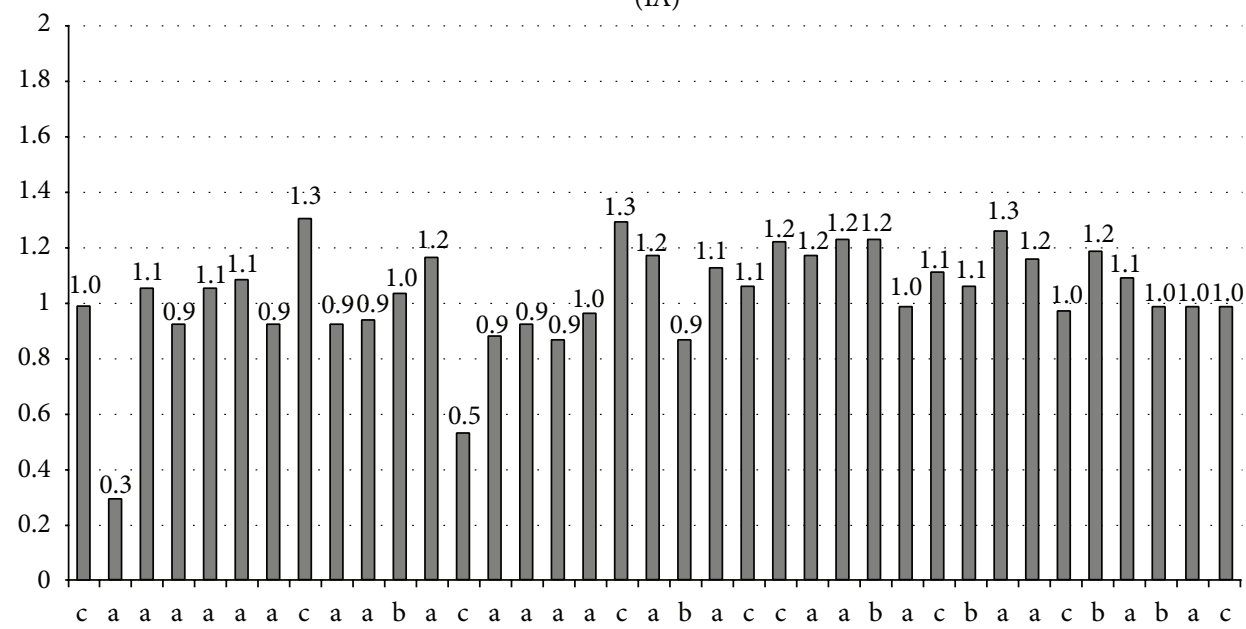

(IIA)

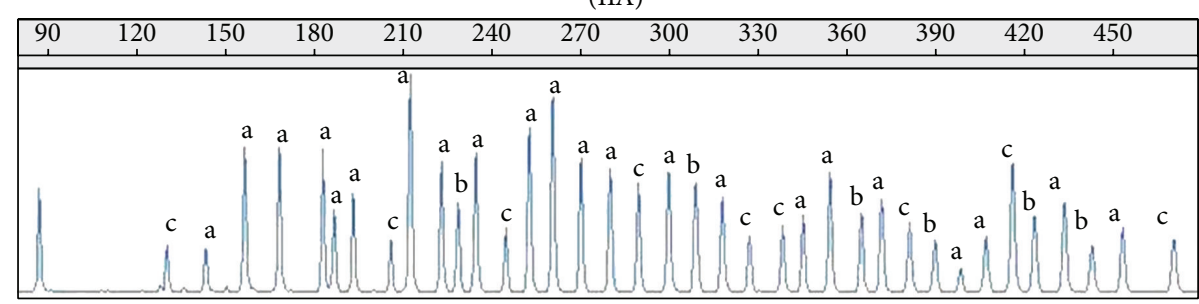

(IB)

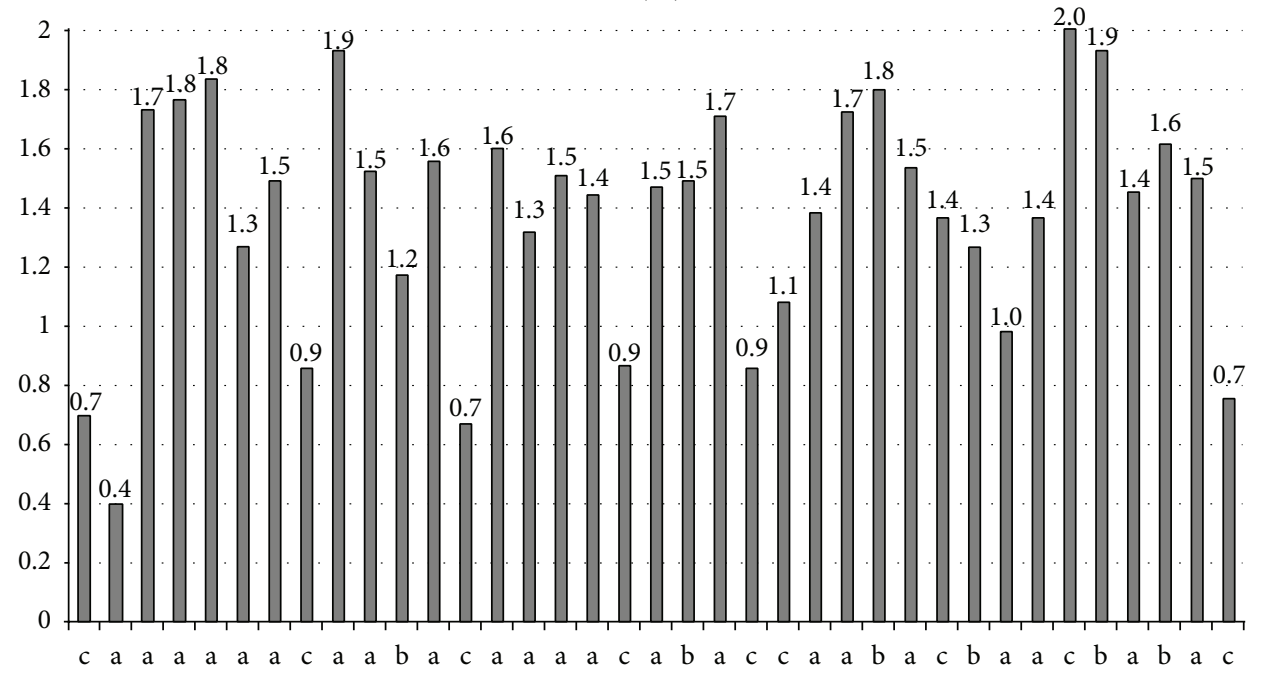

(IIB)

Figure 1: (I) Representative MLPA peak patterns of the IGF1R and IGFBP3 genes. The numbers in the top portion of panels (IA) and (IB) represent the fragment size in the capillary electrophoresis analysis. (II) Histogram showing the normalized data with results of three control individuals and internal controls (reference probes). Normalized relative values, ranging within a confidence interval of 0.7 to 1.3 , were established by control data variations and correspond to two gene copies in the genotype. The values in $y$-axis correspond to the normalized relative value and the number on the top of each bar represents the normalized value for each probe. (A) Normal adrenal gland. (B) Adrenocortical tumor with IGFIR and IGFBP3 amplification. Some reference probes in this tumor are also amplified. (a): twenty-two IGF1R probes. (b): six IGFBP3 probes. (c): reference probes. 


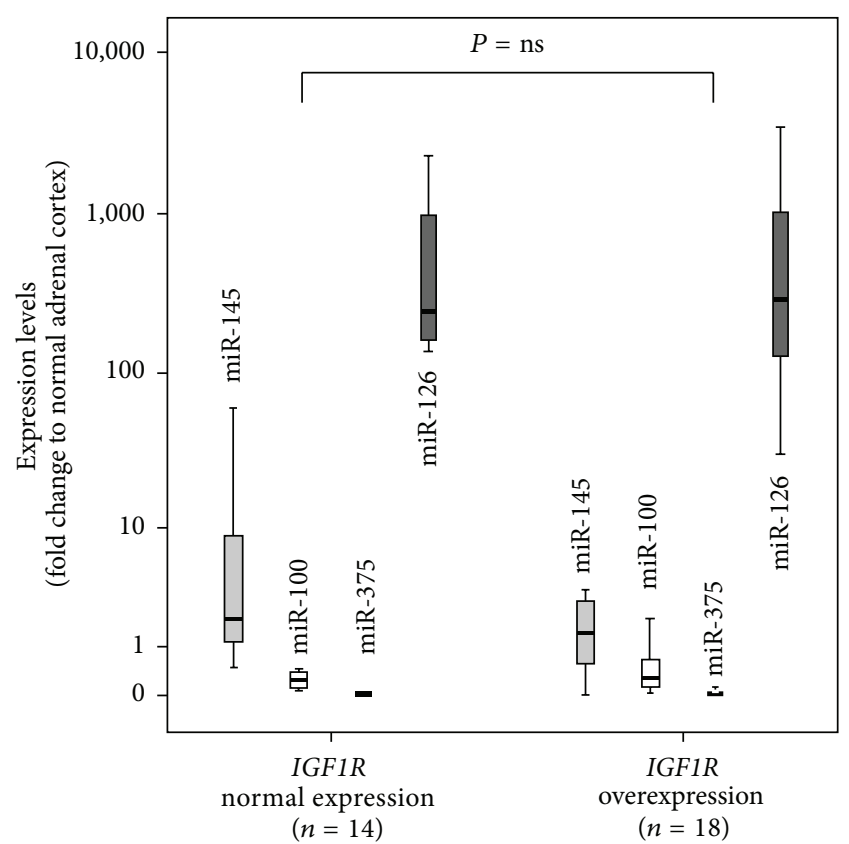

Figure 2: Expression of microRNAs 145, 100, 375, and 126 in adrenocortical tumor samples with normal and increased IGF1R expression. No difference of microRNA expression was observed for all microRNAs. (miR-145 $P=0.19$, miR-100 $P=0.61$, miR-375 $P=0.49$, and $\mathrm{miR}-126 P=0.81)$.

0.01 to 12.6$)$ ) had variable expression in the adrenocortical tumors that were evaluated; however, these values were not correlated with the expression values of IGF1R in adrenocortical adenomas and carcinomas. miR-126 (median 596.6 (from 30.8 to 2667.4)) was overexpressed in benign and malignant adrenocortical tumors and was not related to IGF1R expression (Figure 2).

4.4. Statistical Analysis. Statistical analysis was performed using SPSS Software (PASW version 19.0; SPSS Inc., Chicago, IL). Continuous data are expressed as median values (from minimum to maximum). Differences in expression levels between two groups were analyzed by means of the two-tailed Mann-Whitney $U$ test.

\section{Discussion}

IGF1R has potent mitogenic, antiapoptotic, and transforming activities [17]. Normal growth and differentiation are result of a fine balance between the process of cell proliferation and death, and the disruption of one or more factors involved in these actions can result in pathologic phenotypes, including malignancy [17]. Indeed, IGF1R is overexpressed in several primary tumors and cancer-derived cells $[18,19]$. It has been demonstrated that IGF1R expression is a fundamental prerequisite for cellular transformation because enhanced IGF1R levels and IGF1 signaling are considered key factors for the cell to adopt the proliferative and oncogenic pathways [20]. Increased expression of the human IGF1 receptor promotes ligand-dependent neoplastic transformation in different cells
$[6,21]$. On the other hand, the absence or decrease of levels of the IGF1 receptor prevents malignant growth and transformation [22].

We identified IGF1R overexpression in metastatic pediatric adrenocortical tumors and found that it was a prognostic biomarker of advanced tumors in these children [10]. In present study, we hypothesized that IGF1R overexpression in adrenocortical tumors could be caused by gene amplification, allelic variants, and dysregulated microRNA expression. In fact, IGF1R amplification has been reported in malignant melanomas [23], breast cancers [24], pancreatic adenocarcinomas [25], gastric cell lines [26], rhabdomyosarcomas [27], Wilms' tumors [28], and gastrointestinal stromal tumors [29]. Moreover, IGF1R amplification was associated with cellular transformation and tumor progression [30].

The IGF1R copy number in 64 adrenal tumor samples was analyzed using MLPA in this study. Amplification of $I G F 1 R$ was detected in only one adrenocortical carcinoma (Weiss score 7) that was diagnosed in a woman who had an endocrine hyperfunction that was characterized by hypercortisolism and hyperandrogenism. This patient was treated with mitotane and she had a favorable evolution over the previous 10 years. As expected, the adrenocortical tumor with IGF1R amplification diagnosed in this patient had higher IGF1R mRNA levels compared to normal adrenal samples. MLPA analysis also demonstrated a multiplegene amplification, suggesting a potential aneuploidy. IGF1R gene amplification was not demonstrated in the remaining adrenocortical tumors, which suggested that other mechanisms could be implicated in IGF1R upregulation. Additionally only the previously known exomic and intronic polymorphisms were observed in tumors with or without IGF1R overexpression.

Stimulatory and inhibitory transcription factors determine the level of $I G F 1 R$ expression, and, consequently, the proliferative cell status. The IGF1R gene is controlled by a number of tumor suppressors, including p53, which is the most frequently mutated molecule in human cancer. P53 was able to suppress IGF1R promoter activity by approximately $90 \%$, whereas its mutant forms were associated with IGF1R upregulation [31]. A specific germinative mutation (p. $\mathrm{R} 337 \mathrm{H}$ ) that affected the tetramerization domain of $\mathrm{p} 53$ has been identified in high frequency in Brazilian children with adrenocortical tumors $[32,33]$. This unique p53 defect was detected in 22 of the 64 (34.3\%) patients of the Brazilian cohort that was studied here (data not shown). Nevertheless, IGF1R overexpression and gene amplification were not associated with the presence of this p53 mutation. In addition, the adrenocortical carcinoma with IGF1R amplification did not harbor the p.R337H mutation in blood or tumor tissue DNA (data not shown).

MicroRNA abnormalities are potential mechanisms that may be associated with IGF1R overexpression. Calin et al. [34] demonstrated that more than $50 \%$ of microRNA genes were located in cancer-associated genomic regions. In the present work, we demonstrated that the expression of miR-100 and 375 was decreased in benign and malignant adrenocortical tumors; however, no correlation was found between the selected microRNAs and IGF1R expression. miR-145 also did not correlate with IGF1R expression values. Our data 
corroborate with those from previous studies that showed that miR-100 and 375 expression was decreased in adrenocortical tumors and could be tumor suppressor microRNAs $[11,35]$. In addition, Doghman et al. [11] showed that miR100 regulated the expression of IGF1R and mTOR signaling in adrenocortical cells by modulating the expression of key proteins involved in these pathways [11]. miR-375 is also downregulated in gastric cancers and hepatocellular carcinomas [15]. Previous studies in esophagus carcinoma cells showed that miR-375 has a tumor suppressor effect by inhibiting IGF1R [15]. Shi et al. [14] identified that IGF1R and its docking protein, the insulin receptor substrate-I, are targets of miR-145. miR-126 was overexpressed in benign and malignant adrenocortical tumors. This microRNA suppresses endothelial migration by targeting a set of genes in cancer cells that drive endothelial migration, by activating IGF1R, which is a promoter of endothelial migration, and inhibiting the endothelial MERTK receptor, which is a suppressor of endothelial migration [16].

In conclusion, we detected concurrent IGF1R gene copy number variation and $I G F 1 R$ overexpression in a single functioning malignant adrenocortical tumor. This data suggests that the IGF1R overexpression, which is common in pediatric adrenocortical tumors, is not driven by increased gene copy number. In addition, IGF1R polymorphisms and the abnormal expression of the microRNAs miR-100, miR145, miR-375, and miR-126 did not correlate with IGF1R overexpression in these tumors.

\section{Conflict of Interests}

The authors declare no duality of financial interest or direct or indirect conflict of interests on the part of any author of this paper.

\section{Acknowledgments}

This work was supported by Fundação de Amparo à Pesquisa do Estado de São Paulo (FAPESP) Grant nos. 2008/516186 and 2010/09503-7 (to Tamaya Castro Ribeiro) and Brazilian Grants from Conselho Nacional de Desenvolvimento Científico e Tecnológico (CNPq no. 304678/2012 for Alexander Augusto Jorge and no. 302825/2011-8 to Ana Claudia Latronico).

\section{References}

[1] F. M. Barlaskar and G. D. Hammer, "The molecular genetics of adrenocortical carcinoma," Reviews in Endocrine and Metabolic Disorders, vol. 8, no. 4, pp. 343-348, 2007.

[2] R. Sandrini, R. C. Ribeiro, and L. DeLacerda, "Childhood adrenocortical tumors," Journal of Clinical Endocrinology and Metabolism, vol. 82, no. 7, pp. 2027-2031, 1997.

[3] A. C. Latronico and G. P. Chrousos, "Extensive personal, experience: adrenocortical tumors," Journal of Clinical Endocrinology and Metabolism, vol. 82, no. 5, pp. 1317-1324, 1997.

[4] C. Fottner, A. Hoeflich, E. Wolf, and M. M. Weber, "Role of the insulin-like growth factor system in adrenocortical growth control and carcinogenesis," Hormone and Metabolic Research, vol. 36, no. 6, pp. 397-405, 2004.

[5] H. Yu and T. Rohan, "Role of the insulin-like growth factor family in cancer development and progression," Journal of the National Cancer Institute, vol. 92, no. 18, pp. 1472-1489, 2000.

[6] D. LeRoith and C. T. Roberts Jr., "The insulin-like growth factor system and cancer," Cancer Letters, vol. 195, no. 2, pp. 127-137, 2003.

[7] P. D. Ryan and P. E. Goss, "The emerging role of the insulinlike growth factor pathway as a therapeutic target in cancer," Oncologist, vol. 13, no. 1, pp. 16-24, 2008.

[8] Y. Xie, B. Skytting, G. Nilsson, B. Brodin, and O. Larsson, "Expression of insulin-like growth factor-1 receptor in synovial sarcoma: association with an aggressive phenotype," Cancer Research, vol. 59, no. 15, pp. 3588-3591, 1999.

[9] A. Ouban, P. Muraca, T. Yeatman, and D. Coppola, "Expression and distribution of insulin-like growth factor-1 receptor in human carcinomas," Human Pathology, vol. 34, no. 8, pp. 803808, 2003.

[10] M. Q. Almeida, M. C. Fragoso, C. F. P. Lotfi et al., "Expression of insulin-like growth factor-II and its receptor in pediatric and adult adrenocortical tumors," Journal of Clinical Endocrinology and Metabolism, vol. 93, no. 9, pp. 3524-3531, 2008.

[11] M. Doghman, A. El Wakil, B. Cardinaud et al., "Regulation of insulin-like growth factor-mammalian target of rapamycin signaling by MicroRNA in childhood adrenocortical tumors," Cancer Research, vol. 70, no. 11, pp. 4666-4675, 2010.

[12] J. P. Schouten, C. J. McElgunn, R. Waaijer, D. Zwijnenburg, F. Diepvens, and G. Pals, "Relative quantification of 40 nucleic acid sequences by multiplex ligation-dependent probe amplification," Nucleic Acids Research, vol. 30, no. 12, article e57, 2002.

[13] K. J. Livak and T. D. Schmittgen, "Analysis of relative gene expression data using real-time quantitative PCR and the 2$\Delta \Delta C T$ method," Methods, vol. 25, no. 4, pp. 402-408, 2001.

[14] B. Shi, L. Sepp-Lorenzino, M. Prisco, P. Linsley, T. Deangelis, and R. Baserga, "Micro RNA 145 targets the insulin receptor substrate-1 and inhibits the growth of colon cancer cells," The Journal of Biological Chemistry, vol. 282, no. 45, pp. $32582-$ 32590, 2007.

[15] K. L. Kong, D. L. W. Kwong, T. H. Chan et al., "MicroRNA-375 inhibits tumour growth and metastasis in oesophageal squamous cell carcinoma through repressing insulin-like growth factor 1 receptor," Gut, vol. 61, no. 1, pp. 33-42, 2012.

[16] N. Halberg, C. Alarcón, and S. F. Tavazoie, "microRNA regulation of cancer-endothelial interactions: vesicular microRNAs on the move," The EMBO Journal, vol. 31, no. 17, pp. 3509-3510, 2012.

[17] H. Werner and C. T. Roberts Jr., "The IGFI receptor gene: a molecular target for disrupted transcription factors," Genes Chromosomes and Cancer, vol. 36, no. 2, pp. 113-120, 2003.

[18] H. Werner and D. LeRoith, "The role of the insulin-like growth factor system in human cancer," Advances in Cancer Research, vol. 68, pp. 184-223, 1996.

[19] C. S. Mitsiades, N. S. Mitsiades, C. J. McMullan et al., "Inhibition of the insulin-like growth factor receptor-1 tyrosine kinase activity as a therapeutic strategy for multiple myeloma, other hematologic malignancies, and solid tumors," Cancer Cell, vol. 5, no. 3, pp. 221-230, 2004.

[20] H. Werner and S. Maor, "The insulin-like growth factor-I receptor gene: a downstream target for oncogene and tumor suppressor action," Trends in Endocrinology \& Metabolism, vol. 17 , no. 6 , pp. 236-242, 2006. 
[21] A. Grimberg and P. Cohen, "Role of insulin-like growth factors and their binding proteins in growth control and carcinogenesis," Journal of Cellular Physiology, vol. 183, no. 1, pp. 1-9, 2000.

[22] C. Sell, M. Rubini, R. Rubin, J. P. Liu, A. Efstratiadis, and R. Baserga, "Simian virus 40 large tumor antigen is unable to transform mouse embryonic fibroblasts lacking type 1 insulin-like growth factor receptor," Proceedings of the National Academy of Sciences of the United States of America, vol. 90, no. 23, pp. 1121711221, 1993.

[23] J. Zhang, J. M. Trent, and P. S. Meltzer, "Rapid isolation and characterization of amplified DNA by chromosome microdissection: identification of IGF1R amplification in malignant melanoma," Oncogene, vol. 8, no. 10, pp. 2827-2831, 1993.

[24] A. Almeida, M. Muleris, B. Dutrillaux, and B. Malfoy, "The insulin-like growth factor I receptor gene is the target for the 15 q26 amplicon in breast cancer," Genes Chromosomes and Cancer, vol. 11, no. 1, pp. 63-65, 1994.

[25] G. Armengol, S. Knuutila, F. Lluís, G. Capellà, R. Miró, and M. R. Caballín, "DNA copy number changes and evaluation of MYC, IGF1R, and FES amplification in xenografts of pancreatic adenocarcinoma," Cancer Genetics and Cytogenetics, vol. 116, no. 2, pp. 133-141, 2000.

[26] N. Sugimoto, I. Imoto, Y. Fukuda et al., "IQGAP1, a negative regulator of cell-cell adhesion, is upregulated by gene amplification at 15q26 in gastric cancer cell lines HSC39 and 40A," Journal of Human Genetics, vol. 46, no. 1, pp. 21-25, 2001.

[27] J. A. Bridge, J. Liu, S. J. Qualman et al., "Genomic gains and losses are similar in genetic and histologic subsets of rhabdomyosarcoma, whereas amplification predominates in embryonal with anaplasia and alveolar subtypes," Genes Chromosomes and Cancer, vol. 33, no. 3, pp. 310-321, 2002.

[28] R. Natrajan, J. S. Reis-Filho, S. E. Little et al., "Blastemal expression of type I insulin-like growth factor receptor in Wilms' tumors is driven by increased copy number and correlates with relapse," Cancer Research, vol. 66, no. 23, pp. 11148-11155, 2006.

[29] C. Tarn, L. Rink, E. Merkel et al., "Insulin-like growth factor 1 receptor is a potential therapeutic target for gastrointestinal stromal tumors," Proceedings of the National Academy of Sciences of the United States of America, vol. 105, no. 24, pp. 83878392, 2008.

[30] A. A. Samani, S. Yakar, D. LeRoith, and P. Brodt, "The role of the IGF system in cancer growth and metastasis: overview and recent insights," Endocrine Reviews, vol. 28, no. 1, pp. 20-47, 2007.

[31] H. Werner, E. Karnieli, F. J. Rauscher III, and D. LeRoith, "Wildtype and mutant p53 differentially regulate transcription of the insulin-like growth factor I receptor gene," Proceedings of the National Academy of Sciences of the United States of America, vol. 93, no. 16, pp. 8318-8323, 1996.

[32] R. C. Ribeiro, F. Sandrini, B. Figueiredo et al., "An inherited p53 mutation that contributes in a tissue-specific manner to pediatric adrenal cortical carcinoma," Proceedings of the National Academy of Sciences of the United States of America, vol. 98, no. 16, pp. 9330-9335, 2001.

[33] A. C. Latronico, E. M. Pinto, S. Domenice et al., "An inherited mutation outside the highly conserved DNA-binding domain of the 533 tumor suppressor protein in children and adults with sporadic adrenocortical tumors," Journal of Clinical Endocrinology and Metabolism, vol. 86, no. 10, pp. 4970-4973, 2001.

[34] G. A. Calin, C. Sevignani, C. D. Dumitru et al., "Human microRNA genes are frequently located at fragile sites and genomic regions involved in cancers," Proceedings of the
National Academy of Sciences of the United States of America, vol. 101, no. 9, pp. 2999-3004, 2004.

[35] Z. Tombol, P. M. Szabo, V. Molnar et al., "Integrative molecular bioinformatics study of human adrenocortical tumors: microRNA, tissue-specific target prediction, and pathway analysis," Endocrine-Related Cancer, vol. 16, no. 3, pp. 895-906, 2009. 


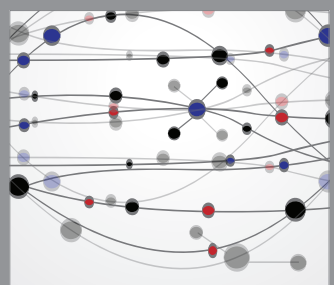

The Scientific World Journal
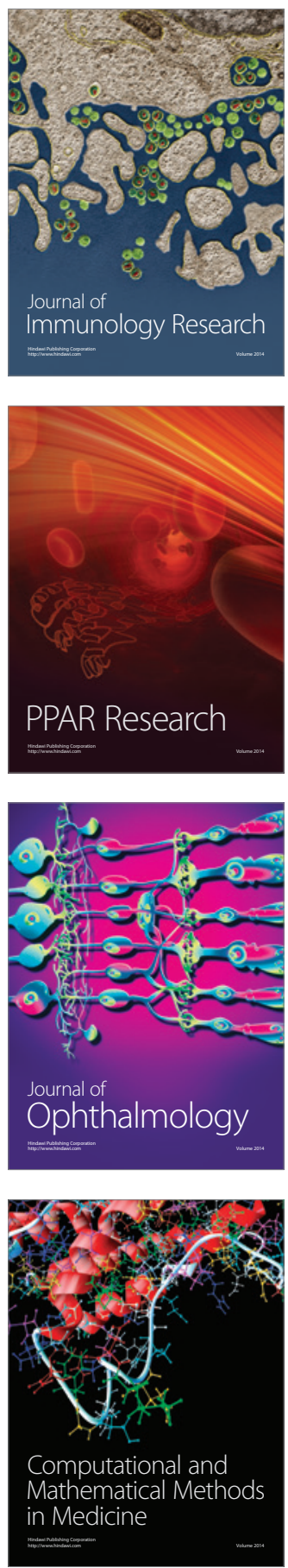

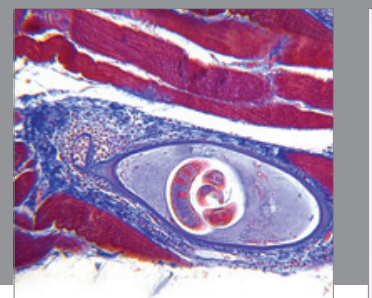

Gastroenterology

Research and Practice
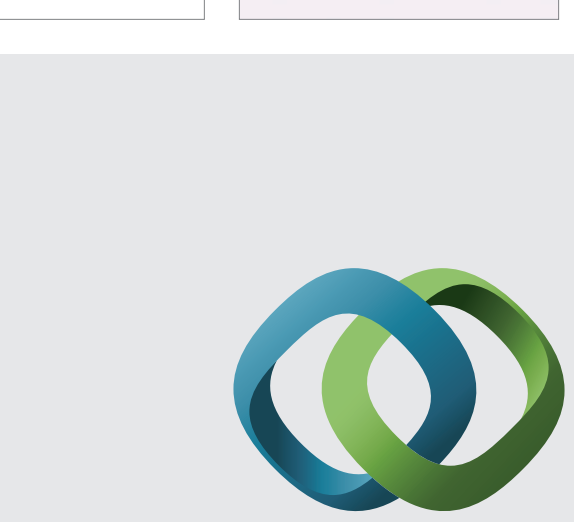

\section{Hindawi}

Submit your manuscripts at

http://www.hindawi.com
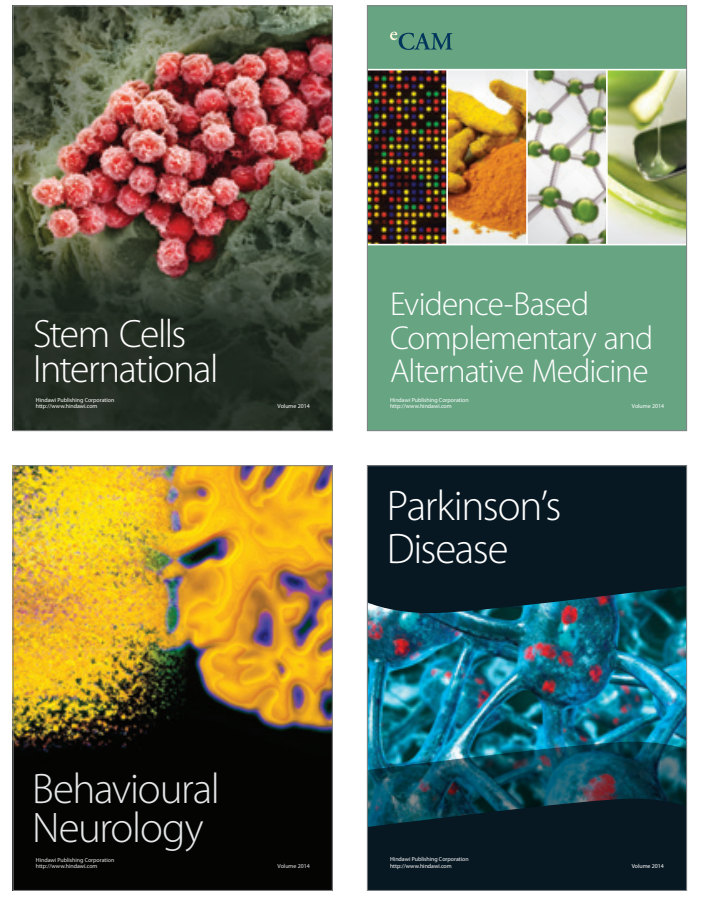
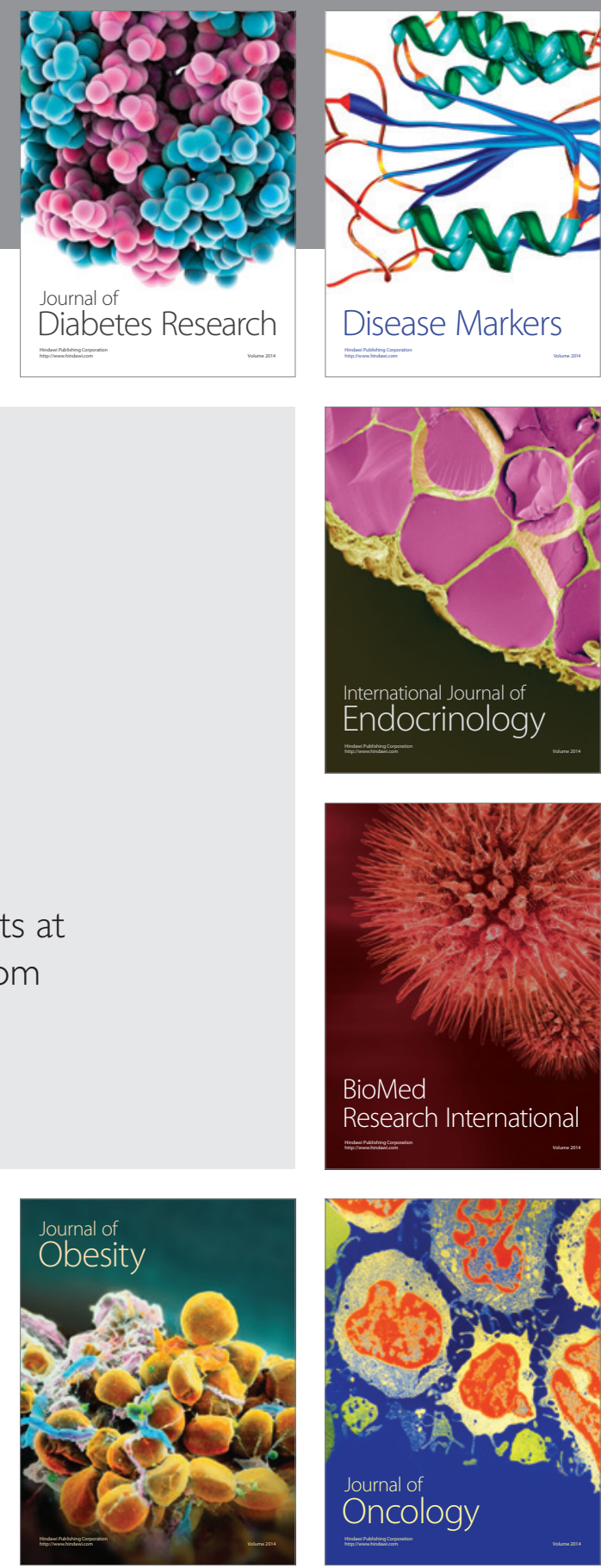

Disease Markers
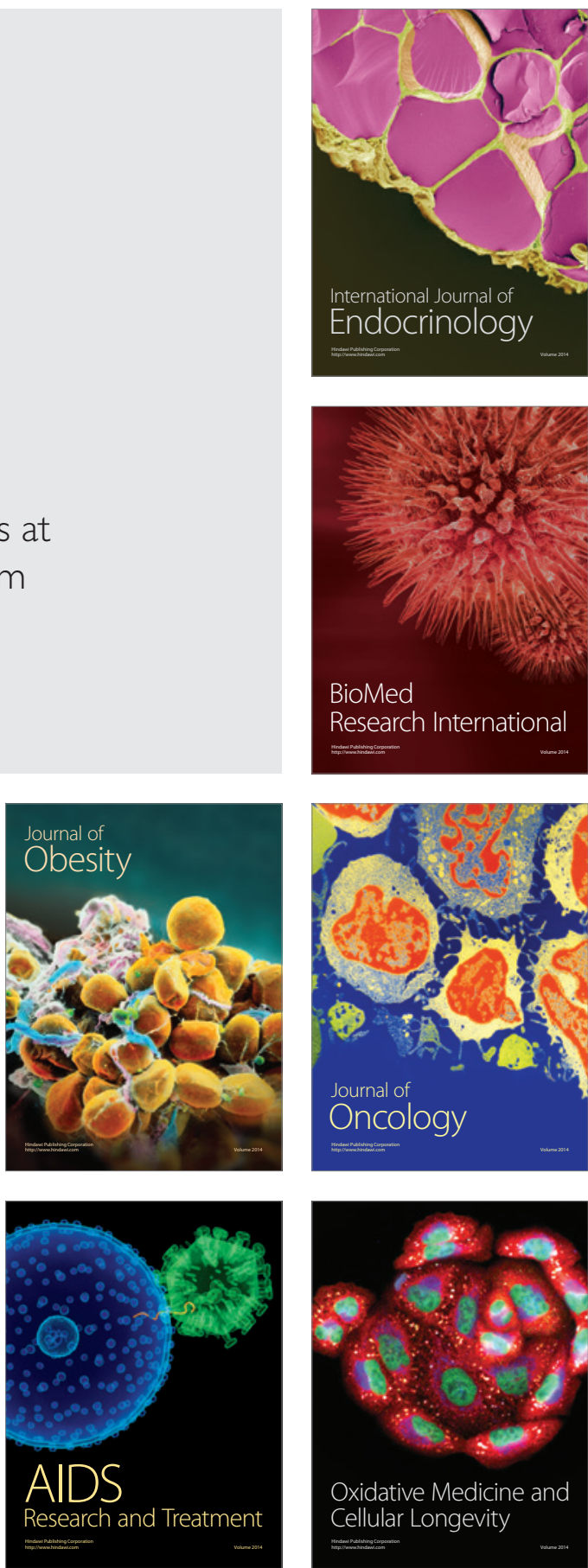